\title{
Anti-tuberculosis treatment defaulting. An analysis of perceptions and interactions in Chiapas, Mexico
}

\author{
Ivett Reyes-Guillén, MSc, (I) Héctor Javier Sánchez-Pérez, $\mathrm{PhD},(1,2)$ \\ Jorge Cruz-Burguete, $\mathrm{PhD}$, (1) Miren Izaurieta-de Juan, $\mathrm{PhD}{ }^{(3)}$
}

\begin{abstract}
Reyes-Guillén I, Sánchez-Pérez HJ, Cruz-Burguete J, Izaurieta-de Juan M. Anti-tuberculosis treatment defaulting. An analysis of perceptions and interactions in Chiapas, Mexico. Salud Publica Mex 2008;50:25I-257.
\end{abstract}

\begin{abstract}
Objective.To analyze the perceptions and interactions of the actors involved in anti-tuberculosis treatment, and to explore their influence in treatment defaulting in Los Altos region of Chiapas, Mexico. Material and Methods. From November 2002 to August 2003, in-depth interviews were administered to patients with PTB, patients' family members, institutional physicians, community health coordinators, and traditional medicine practitioners. Results. We found different perceptions about PTB between patients and their families and among health personnel, as well as communication barriers between actors. Defaulting is considered to be mainly due to the treatment's adverse effects. Conclusions. It is necessary to conduct research and interventions in the studied area with the aim of changing perceptions, improving sensitization, quality and suitability of management of patients with PTB in a multicultural context, and promoting collaboration between institutional and traditional medicine.
\end{abstract}

Key words: pulmonary tuberculosis; patient dropouts; perceptions; Mexico
Reyes-Guillén I, Sánchez-Pérez HJ,

Cruz-Burguete J, Izaurieta-de Juan M.

Abandono del tratamiento antituberculosis. Un análisis de percepciones e interacciones en Chiapas, México. Salud Publica Mex 2008;50:25I-257.

\section{Resumen}

Objetivo. Analizar percepciones e interacciones entre actores involucrados en el tratamiento antituberculosis y su influencia en el abandono del tratamiento en los Altos de Chiapas, México. Material y métodos. De noviembre 2002 a agosto 2003, se realizaron entrevistas a profundidad a pacientes con TBP, familiares, médicos institucionales, coordinadores comunitarios de salud y médicos tradicionales. Resultados. Se encontraron diferentes percepciones entre los pacientes y sus familiares, respecto a las del personal de salud, así como barreras de comunicación entre los distintos actores. Los efectos adversos del tratamiento antituberculosis, son consideradas como una de las principales causas de su abandono. Conclusiones. Es necesario que en la región estudiada se realicen investigaciones e intervenciones encaminadas a: cambiar percepciones y mejorar la sensibilidad, calidad y adecuación del manejo de pacientes con TBP en contextos multiculturales, así como impulsar el trabajo conjunto entre la medicina institucional y tradicional.

Palabras clave: tuberculosis pulmonar; desistencia del paciente; percepciones; México

(I) El Colegio de la Frontera Sur (Ecosur). México.

(2) Grupos de Investigación para América y África Latinas. México.

(3) Asociación Mexicana de Psicoterapia Analítica de Grupo. México. 
$\mathrm{T}$ he Pulmonary Tuberculosis Control Program in Chiapas is based on the Directly Observed Therapy Strategy (DOTS). ${ }^{1}$ However, diverse organizational aspects -notably a shortage of resources, suitably trained personnel and lack of supervision- mean that their impact is very limited. ${ }^{2}$ For the patients, even when therapy is free, the high levels of poverty and inaccessibility of health services make treatment under the DOTS difficult. The result of all of this is low cure rates. ${ }^{2}$ In 2002, the PTB incidence rate for Mexico was 21.01 per 100000 inhabitants, whereas in Chiapas it was 43.2 and, in contrast, only 4.8 in Guanajuato. ${ }^{3}$

In terms of mortality associated with PTB, in 2002 the rate for women was 2.3 per 100000 in Mexico and 6.5 in Chiapas, but in the Federal District (Mexico City) it was only 0.7 per 100000 . Among men, the corresponding rates were 5.4, 12.9 and 1.6 per 100000 , respectively. ${ }^{3}$

In the Chiapas region of Los Altos, according to Ministry of Health records, from 2001 to 2003 the cure rate for PTB was $61.7 \%$, while in $4.2 \%$ the treatment failed, $7 \%$ defaulted, $7.3 \%$ died, $8 \%$ were referred, and in an additional $11.8 \%$ the treatment outcome was unknown. According to other studies, only $16 \%$ of PTB patients are treated via DOTS, in contrast with the official figure for Mexico of 70 percent. $^{4}$

In this context, defaulting from anti-tuberculosis treatment also constitutes an important barrier to its control, ${ }^{5}$ an aspect which particularly affects the Los Altos Region. ${ }^{4}$ Although no precise data exists on the incidence of PTB in Los Altos, in areas of high levels of poverty in Chiapas the prevalence of PTB in the population aged 15 years and over is around 277 per 100000 inhabitants, with under $30 \%$ of cases receiving anti-tuberculosis treatment and rates of under-diagnosis that range between $34 \%$ in the hospital context to over $70 \%$ in communities. ${ }^{6}$

Given that the conception of a disease and the response to it are influenced by social, cultural, economic and political values -which together shape symbolic structures and which translate into forms of thinking in accordance with the immediate environment- ${ }^{7}$ the present research was carried out with the aim of examining the perceptions and interactions of the actors involved in anti-tuberculosis treatment. This research, therefore, included conceptions regarding PTB and its treatment, as well as the identification of perceived treatment-related problems which may influence defaulting in Los Altos, one of the poorest regions, and one with a high indigenous population (Mayan Indians) not only in Chiapas, but also in the country as a whole. ${ }^{2}$

Perceptions are articulator elements for the comprehension and analysis of both individual and group actions. Perception is a cognitive process through which the environment is dimensioned as a function of the point of view and character of each individual. In this sense, and from the medical-anthropological viewpoint, all diseases represent social-historical processes that need to be reconstructed in order to understand their current meanings. ${ }^{7-8}$ Interactions of the actors are the relationships among different social actors involved in a particular issue. ${ }^{9-11}$

Even though defaulting from anti-tuberculosis treatment has been studied in many places and with different approaches, very few studies have tackled it from the perspectives of the patient's family, health services providers, and even the patients themselves -all of which interact during anti-tuberculosis treatment-. This situation acquires even greater relevance in contexts where two or more distinct cultures coexist (for example, indigenous and non-indigenous), and where there is high poverty, in general, being places where PTB has high prevalence.

\section{Study population and methods}

Los Altos is a region with some of the poorest health conditions in Chiapas and Mexico. ${ }^{12}$ It has 10 of the 50 poorest municipalities in the country and it has the highest proportion of indigenous population. Less than $20 \%$ of its 422269 inhabitants have any form of social security ${ }^{12}$ and the majority have insufficient resources to be able to have access to private services. Consequently, both public health services and traditional medicine are extensively used by the population. ${ }^{2,12}$

Between November 2002 and August 2003, indepth interviews were administered to all the different actors involved in anti-tuberculosis treatment in the Los Altos localities with more registered PTB cases. These actors are: patients with PTB, patients' family members, institutional medicine physicians, community health coordinators (formerly known as "primary care technicians") and traditional medicine practitioners. A series of guiding, open-ended questions were prepared for use in the in-depth interviews for each one of these actors. The interviews were carried out separately and in private by the project's principal investigator, who has extensive experience in community work in multicultural environments. Patients and their families were interviewed in their homes, and health workers in their workplaces. It was only necessary to employ interpreters with two patients; all other interviews were conducted in Spanish.

Patients with PTB. Based on the results of a previous study, ${ }^{13}$ the communities with the most patients with PTB were identified: San Cristóbal de Las Casas $(n=17$ 
cases), Teopisca ( $n=3)$, and San Juan Chamula $(n=3)$. According to Ministry of Health records, $50.3 \%$ of patients with PTB in Los Altos come from these communities. All these patients had received anti-tuberculosis treatment two to three years before the present study was conducted.

Of the 23 patients with PTB sought (18 indigenous; six women and 17 men), four had died from PTB (three indigenous); eight could not be traced (seven indigenous); two indigenous refused, and nine agreed to participate (table I). Those patients who still had a cough were asked to provide samples for culturing and for drug sensitivity, and these were processed according to current Mexican regulations. ${ }^{14}$

Patient family members. Thirteen family members were interviewed, who correspond to the nine interviewed patients and one who had died due to PTB.

Institutional medicine physicians. All physicians $(n=8)$ involved in tuberculosis prevention and control in the communities studied were included: program coordinators (at state, health district and local levels), treating physicians, and zone supervisors. Three of them had participated in the treatment of at least one patient, and only one speaks a native language.

Community health coordinators. These are community health technicians who perform epidemiological surveillance and administer anti-TB treatment via DOTS. They speak an indigenous language and play a role as liaison between patients and health services. Nine of the regional 19 community health coordinators were interviewed (the rest refused due to "lack of time" -despite urging by their immediate superiors to participate in the study-). Of those interviewed, four participated in the treatment of the studied patients.

Practitioners of traditional medicine: Their diagnoses and treatments involve magical-religious aspects. Representatives of traditional medicine practicing in the study area were interviewed (all of them have treated patients with PTB):

- An herbalist (who uses medicinal plants) from the most important organization for traditional medicine practitioners in the region (Chiapas Indigenous Medicine Organization);

- A spiritualist who deals with "spiritual-" and "soul-" related problems, basing treatment on prayer, but also prescribing allopathic medicines (for example, vitamins to "fortify the body");

- A practitioner of traditional medicine, the only one in the region whose work is coordinated with institutional medicine (the others have no interaction with institutional medicine as they perceive it as lacking respect for traditional medicine). Given that she combines herbal with allopathic remedies, she is considered a "traditional medicine practitioner in transition". ${ }^{15}$

\section{Ethical aspects}

At the time of the study, there was no ethical review committee in Chiapas. Furthermore, according to Mexican health legislation, ${ }^{16}$ this research is considered as a "low health risk" and does not require approval by a research ethical committee. However, all research

Table I

Sociodemographic indicators of the nine patients studied with PTB. Chiapas, México, 2002-2003

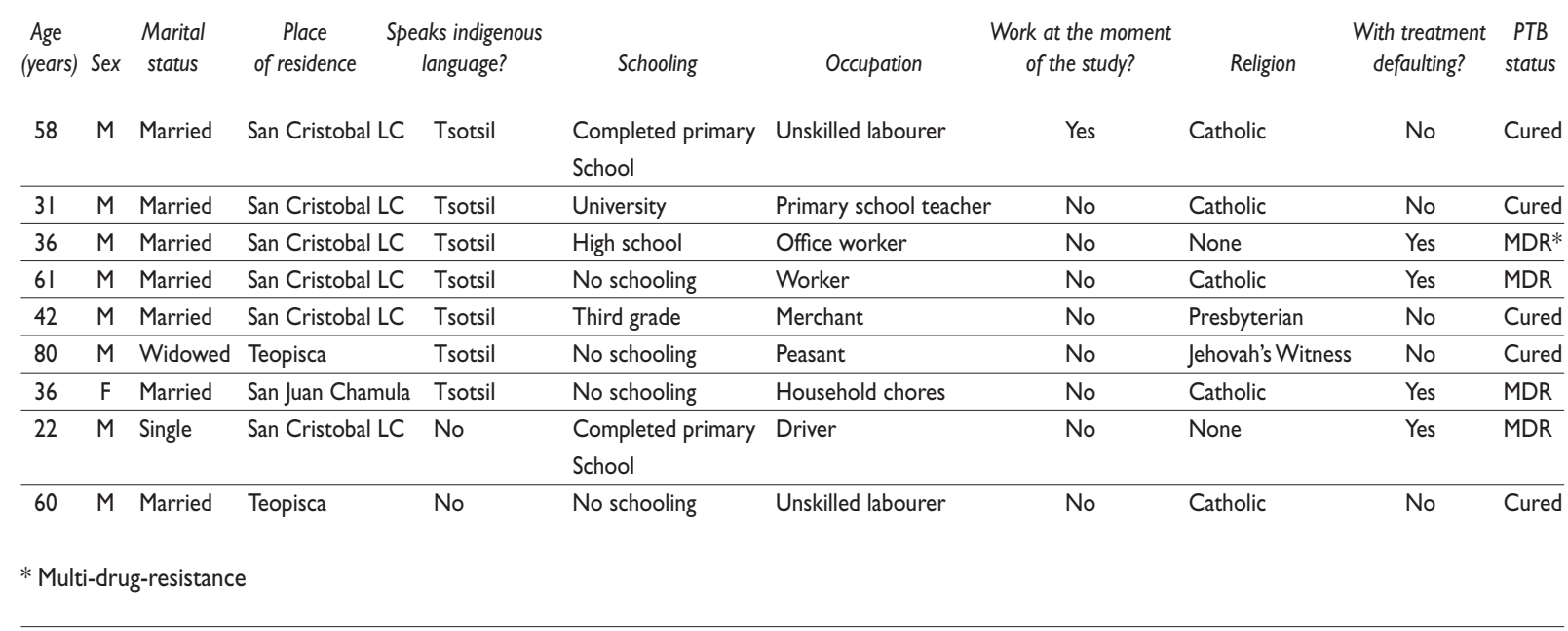


was performed in accordance with the Declaration of Helsinki. ${ }^{17}$

\section{Analysis of the information}

The in-depth interviews were analyzed according to Grounded Theory ${ }^{18}$ by organizing the relationship of the responses from the various actors in terms of conceptions regarding PTB and its treatment, as well as by identifying perceived treatment-related problems.

\section{Results}

Of the nine patients interviewed, five completed treatment and did not present any respiratory symptoms. The other four had defaulted anti-TB treatment at least twice (and presented multi-drug-resistance): two due to secondary effects (dizziness, weakness, physical indisposition); one woman's husband wouldn't let her take the treatment ("if you take that medicine, you feel bad...you'll die"); and one due to alcoholism.

Perceptions about PTB. The patients with PTB perceived it as a problem of an ordinary cough. Their main concerns were that treatment didn't get rid of the cough and it made them feel worse than the PTB itself -due to its adverse effects-; that is, a lack of improvement and feeling weaker. Their worries about PTB were greater when physically unable to work ("before I could work my land, now I can't..."). Among those resorting to traditional medicine, only one case considered it curative; it was common, regardless of ethnicity, that this kind of medicine is used as a complementary, non-curative treatment.

Patients (both defaulting and not) feel poorly understood by institutional physicians and that there is a lack of communication (although they mentioned being well-treated by health personnel); they feel that institutional physicians attach no importance to the malaise that the anti-tuberculosis medication causes.

As a general rule, patients did not believe antituberculosis treatment could cure them, and that, consequently, they would not be able to continue living a normal life, especially with regard to the treatment's adverse effects ("There's no way I'm going to keep taking this medicine if it makes me feel even worse"). Among indigenous patients it was common to hear that "God wanted me to get sick like this, and if I have to die, nothing can be done about it".

The information obtained from patients' families coincided fully with that provided by the patients: they perceived it as a problem of an ordinary cough. In general, they do not know what medication or dosage the patient takes, and they think that defaulting is due to the secondary effects and long duration of treatment. They tend to see traditional medicine as not curing PTB, even though there was one case of a man who obliged his wife to use only traditional medicine. Their main concerns with respect to PTB were seeing their family member ill, not being cured by the treatment, feeling worse when in treatment, and the physicians did not explain or help. They cited problems of a short supply of medicines, constant changes of doctors and long waiting times for receiving medical care. They consider that even though institutional physicians treat the patient well, they receive insufficient information about PTB and inadequate support for dealing with secondary effects, and point out that if the institutional physicians took them into account, they could be of greater use ("The doctor explains nothing to us" -family member of one of the patients-;"... we could help our patient, but they don't listen to us").

Institutional physicians and community health coordinators recognize that secondary reactions to the therapy are the main causes of defaulting. Physicians consider these reactions to be "normal" and that they can only treat gastric problems ("they start complaining about stomach pain... but we can't do anything, the treatment is like that, we only help out with antacids and food supplements" -institutional physician-). Other factors mentioned in treatment defaulting were: lack of commitment on the part of patients, negative family influence that can hinder treatment, and; negative doctor-patient relationships (problems in attitudes, poor communication and disinterest on both sides). Among aspects which worry health personnel most about PTB are: treatment defaulting, multi drug-resistance, lack of access to health services and the tuberculosis program's low budget.

Furthermore, for institutional physicians, traditional medicinal knowledge has no validity for PTB treatment. Similarly, the community health coordinators see themselves as superior to traditional medicine practitioners, who they see as rivals; the traditional practitioners see the community health coordinators as a source of conflict in the communities because of their contempt of traditional medicine.

Traditional medicine practitioners conceptualize PTB as a cough resulting from complication of influenza. They consider anti-TB treatment defaulting as arising from its long duration, secondary reactions and ignorance on the part of the patient about the disease and its treatment. They feel that patients often simply do not want to be cured, and "when a patient wants to die, nothing can be done about it." Moreover, they believe that institutional physicians do nothing to make the 
therapy shorter or to avoid the patient's suffering. With the exception of the spiritualist who refers his patients to institutional physicians, practitioners consider they can cure PTB with treatments based on certain specific herbal remedies that reduce coughing and strengthen the lungs, with treatment lasting from 2 to 6 weeks, depending on severity ("we can cure them in a week or so... we can cure more quickly" -traditional herbalist).

\section{Interactions among the actors}

Interactions found among the various actors are complex, although in some cases there is no interaction at all:

- Patients are supported by their family. With the exception of one patient who fainted once from the medication (and whose husband forbid her to continue), families encourage the patient to adhere to treatment. There were no data to suggest any discrimination or stigmatization of PTB patients within the family.

- Patients mentioned that institutional physicians do not explain what is happening, doctors change constantly, and their medication is often not available. Institutional physicians consider that patients complain too much and that the secondary reactions they experience are largely due to "not eating properly." Similarly, institutional physicians generally maintain a rather distant doctor-patient relationship, not getting involved in the physical and emotional condition of patients, scolding them to take their medication, and never going to their home when they are unable to go to the health unit.

- Patients and their families have a much better relationship (in terms of trust and communication) with traditional medicine practitioners than with institutional physicians, since the former will listen to the patient, try to help them, and agree that institutional therapy is very long and has adverse effects. In addition, traditional medicine practitioners take into consideration that the family helps the patient and checks to ensure they take their medication.

- Patients' family members noted a lack of communication with institutional physicians and community health coordinators who, in the best of cases, merely hand over the anti-tuberculosis medication to the patient but provide no further explanations. Neither the institutional physicians nor the community health coordinators take the family into account, not seeing them as a potential factor in providing support for the anti-tuberculosis treatment.
- There is no relationship between institutional and traditional medicine.

\section{Discussion}

The Tuberculosis Control Program in the studied area is very poor: among other factors, the situation is unknown for a high proportion of patients, there is evidence of high mortality, high levels of defaulting, multi-drug resistance, and personnel are not well-trained. The following aspects are particularly notable:

a) Perceptions regarding PTB are similar between patients and their families, but this view differs from that of the institutional physicians, and this may be considered an inter-actor communication barrier. One repercussion is that patients and their families do not have appropriate information about PTB and are not aware of the importance of strict adherence to their anti-tuberculosis treatment. In this regard, lack of information from health workers about PTB is a predictor of non-compliance of anti-tuberculosis treatment. ${ }^{19}$

b) That institutional physicians don't give sufficient support for dealing with secondary effects and do not take either patients or their families into account constitutes a barrier to communication. If patients and their families are met with disinterest, indifference, and different perceptions and attitudes on the part of health personnel, it will be difficult to get them to change behavior patterns regarding anti-tuberculosis therapy. Our results underline the fact that for defaulting, structural barriers are more important than cultural differences. ${ }^{20}$ If patients with PTB repeatedly interrupt therapy, chronicity and multi-drug resistance are favored. ${ }^{21}$ In this study, the four patients who had defaulted at least once were multi-drug resistant.

Although it was not possible to document cases of over-dosage in treatment, one of the main reasons indicated for defaulting was secondary effects, considered to be more harmful than PTB itself. In this sense, there was a notable incapacity on the part of institutional physicians to manage patients. This is important to consider because in malnourished patients these effects are usually amplified $^{22}$ and Chiapas is the Mexican state with the highest levels of malnutrition. ${ }^{2}$

c) Despite the majority of patients being indigenous, little use was apparently made of traditional medicine. Based on our findings, it appears that this type of medicine is used for complementary treatment, 
or as an alternative in dealing with the secondary effects of anti-tuberculosis treatment. However, since the use of traditional medicine is widely recognized in the region, particularly among the indigenous population, it is also possible that the interviewed patients, for cultural reasons, did not fully declare their utilization of these services. ${ }^{23}$

Similarly, there was a notable lack of any link between institutional and traditional medicine due to the presence of mutual stereotypes. The region studied has one of the highest percentages of indigenous population in Chiapas and traditional medicine comprises part of a cultural system which prevails in many sectors -even some that are non-indigenous- as well as constitutes a complex doctrine regarding health and ill-health; a historical and cultural legacy. ${ }^{23}$ The confluence of two or more cultures implies, apart from sharing territory, the coexistence of different rationalities; something which may be seen as rational from one point of view may well be considered irrational from another. ${ }^{24}$

However, in Los Altos there are no strategies attempting to bring these two types of medicine together in the control of PTB, to not put patients in a position of conflict between institutional and traditional medicine (based mainly on herbal remedies, shorter treatment time, cheaper, and without secondary effects). However, the inefficiency of the Tuberculosis Control Program in the studied region cannot be explained by cultural questions.

Regarding the limitations of the study, the results obtained may be affected by the inefficiency of the Tuberculosis Control Program in the area: in regions where the programs do operate effectively and are centered on the needs of patients, they can counteract mythical beliefs about tuberculosis and reduce defaulting. ${ }^{25}$

\section{Conclusions}

It is necessary to develop interventions involving health personnel in the study area which: modify perceptions; improve sensitization, communication, quality and suitability of management of patients with PTB in a multicultural context; and promote collaboration between institutional and traditional medicine.

\section{Acknowledgements}

We express our thanks to Los Altos Health District of the Chiapas Institute of Health, and to the Chiapas State Indigenous Medicine Organization (OMIECH) for their support of and trust in our work; to Dr. Ernesto Jaramillo Betancour and Dr. Graciela Freyemuth for their invaluable contribution in carrying out the analyses for this research; to Alejandro Flores and Juan Carlos Nájera Ortiz for their invaluable support in the field work.

\section{References}

I. Organización Mundial de la Salud (OMS). Tratamiento de la tuberculosis: directrices para los paradigmas nacionales. Geneva: OMS, 1997. 2. Sánchez-Pérez HJ. La salud enferma de Chiapas. En: Ocampo MR, Espinoza L. (eds). La Guerra en la Paz. México, DF: Universidad Nacional Autónoma de México/Editorial Comuna/El Colegio de la Frontera Sur, 2007:287-324.

3. Secretaría de Salud (SSA). Indicadores de resultado, 2002. Información para la evaluación de los sistemas de salud. Salud Publica Mex 2004;46: 26I-27I.

4. Sánchez-Pérez HJ, Nájera-Ortiz JC. Seguimiento de pacientes con tuberculosis pulmonar en los Altos de Chiapas, México: un análisis de casos de pacientes diagnosticados de 1998 al 2002. In: XXIII Congreso Nacional de Investigación Biomédica. Monterrey, Nuevo León: Universidad Autónoma de Nuevo León, 2005.

5.World Health Organization (WHO). Report on the tuberculosis epidemia 1997. Geneva:WHO, 1998.

6. Sanchez-Perez HJ, Hernan M, Hernandez-Diaz S, Jansa JM, Halperin D, Ascherio A. Detection of pulmonary tuberculosis in Chiapas, Mexico. Annals of Epidemiology 2002; (12)3:166-172.

7. Menéndez LE. Estilos de vida, riesgos y construcción social. Conceptos similares y significados diferentes. Estudios Sociológicos 1998;16:37-67.

8. Corona A, Morales C, Chalgub M, Armas P,Acosta C, González E. Conocimientos, percepciones y prácticas de grupos de población respecto a la tuberculosis 1994-1996. Rev Cubana Med Trop 2000;52(2): $110-114$

9. Checkland P. Systems thinking, systems practice. New York: John Wiley, 1981.

10. Hindess B.Actor and Social Relations. In: M.L. Wardell, S. Turner (Eds.). Sociological Theory in Transition. Boston, Mass:Allen and Unwin, 1986.

I I. Long N, Loog A (Eds.). Battlefields of knowledge. Londres: Rootledge, 1992.

12. Consejo Nacional de Población. Programa de Educación Salud y Alimentación (PROGRESA). Índices de marginación por localidad. Mexico, DF: CONAPO-PROGRESA, 1998.

13. Sánchez-Pérez HJ. Informe final del Proyecto "Tuberculosis pulmonar en los Altos de Chiapas: ‘avances o retrocesos?" San Cristóbal de Las Casas, Chiapas: El Colegio de la Frontera Sur, 2000.

14. SSA. Modificación a la Norma Oficial Mexicana NOM-006-SSA2-1993 para la prevención y control de la tuberculosis en la atención primaria a la salud. Mexico, DF: Diario Oficial de la Federación, 24 de septiembre de 2005.

15. Harman R.C. Cambios Médicos y Sociales en una comunidad mayatzeltal. Mexico, DF: Instituto Nacional Indigenista, 1990.

16. Carbonell M. Ley General de Salud y disposiciones complementarias. Mexico: Porrúa, 2004.

17. World Medical Association. Declaration of Helsinki: ethical principles for medical research involving human subjects. Edinburgh:WMA, 2000.

18. Jones D, Manzelli H, Pecheny M. Grounded Theory. Una aplicación de la teoría fundamentada a la salud. Cinta de Moebio, Issue 019. Santiago de Chile: Universidad de Chile, 2004.

19. Culqui DR, Grijalva CG, Reategui SR, Cajo JM, Suárez LA. Factores pronósticos del abandono del tratamiento antituberculoso en una región endémica del Perú. Rev Panam Salud Publica 2005; I8(I):14-20. 
20. Greene JA. An ethnography of nonadherence: culture, poverty, and tuberculosis in urban Bolivia. Cult Med Psychiatry 2004;28:40I-425.

21. Farmer P,Yong Kim J. Community based approaches to the control of multidrug-resistant tuberculosis: introducing "DOT- plus". BMJ 1998;317:

67I-674.

22. Núñez-Rocha GM, Salinas-Martínez AM,Villareal-Ríos E, GarzaElizondo ME, González-Rodríguez F. Riesgo nutricional en pacientes con tuberculosis pulmonar: ¿cuestión del paciente o de los servicios de salud? Salud Publica Mex 2000;42:126-132.
23. Page J. El mandato de los Dioses. Etnomedicina entre los tzotziles de Chamula y Chenalhó, Chiapas. San Cristóbal de Las Casas, Chiapas:

Programa de Investigaciones Multidisciplinarias sobre Mesoamérica y el Sureste. México, DF: Universidad Nacional Autónoma de Mexico, 2002. 24. Geertz C. Los usos de la diversidad. Barcelona: Paidós, 1996.

25. Jaramillo E. Tuberculosis control in less developed countries: can culture explain the whole picture? Tropical Doctor 1998;28:196-200. 